\title{
Predestinasi
}

Volume 13, No. 1, Juni 2020, Hal. 7- 14

ISSN (Print): 1978-9351

\section{Adaptasi Waria: \\ Studi Kasus Komunitas Waria di Kabupaten Pangkep}

\author{
Faisal Tanjung \\ ${ }^{1}$ Sosiologi/ Universitas Negeri Makassar \\ Email: faisal.tanjung@yahoo.com
}

\begin{abstract}
ABSTRAK
Penelitian ini bertujuan untuk mengetahui (1) Untuk mengetahui bagaimana proses adaptasi waria dalam lingkungan masyarakat (2) Untuk mengetahui bagaimana penerimaan masyarakat terhadap keberadaan waria. Jenis penelitian yang digunakan adalah deskriptif kualitatif yang menggambarkan adaptasi komunitas waria dengan mengambil lokasi di Kelurahan Pa'doangdoangan Kecamatan Pangkajene Kabupaten Pangkep. Penarikan informan dilakukan secara purposive sampling, dan diperoleh sebanyak 14 orang. Tehnik pengumpulan data yang digunakan yaitu observasi, wawancara dan dokumentasi. Hasil penelitian menunjukkan bahwa 1) Proses adaptasi yang dilakukan oleh komunitas waria di Kelurahan Pa`doang-doangan yaitu dengan cara bergaul dan selalu berinterkasi dengan msayarakat dan bagaimana mereka menjunjung tinggi nilai-nilai sikap saling mengahargai kepada setiap individu baik dalam kalangan muda atau dewasa dan yang paling penting ialah mereka tetap menjaga etika. Selain itu, mereka memberikan pelayanan terbaik kepada setiap pelanggannya dan aktif dalam kegiatan sosial kemasyarakatan sehingga tercipta rasa emosional yang tinggi dengan warga masyarakat. 2) Keberadaan waria dalam masyarakat pada awalnya mendapat tekanan-tekanan sosial namun secara perlahan mereka dapat di terima dengan baik dalam masyarakat. Perwujudan dari diterimanya keberadaan komunitas waria di Kelurahan Pa`doang-doangan yaitu mereka tidak hanya di terima dalam lingkungan sosialnya, melainkan mereka mendapat legitimasi dari pemerintah setempat. Kini mereka mendapat peran sosial yang sama dalam lingkungan sosialnya.
\end{abstract}

Kata Kunci: Adaptasi; komunitas; waria

\begin{abstract}
This study aims to see (1) Know how to read waria in the community (2) To see how public acceptance of waria is. The type of research used is descriptive qualitative which describes the adaptation of the transgender community by taking the location in Pa'doang-doangan Village, Pangkajene District, Pangkep Regency. Information retrieval was carried out by purposive sampling, and obtained 14 people. The data techniques used were observation, interview and documentation. The results showed that 1) The adaptation process carried out by the transgender community in Pa'doang-doangan Village is by associating and always interacting with the community and how they uphold the values of mutual respect for each individual both in a young or adult environment and the most important thing is to keep them ethical. In addition, they provide the best service to each of their customers and are active in community social activities so as to create a high emotional sense with community members. 2) The
\end{abstract}




\author{
8 Predestinasi \\ Volume 13, No. 1, Juni 2020 Hal. 7- 14
}

existence of transgender women in society at first received social pressures but slowly they were able to accept it well in society. The manifestation of the acceptance of the existence of the waria community in Pa'doang-doangan Village is that they are not only accepted in their social environment, but they get legitimacy from the local government. Now they have the same social role in their social environment.

Keywords: Adaptation; community; shemale

\title{
PENDAHULUAN
}

Masyarakat merupakan kumpulan dari individu-individu yang hidup bersama, memiliki sejumlah nilai dan norma sosial di dalamnya yang tujuannya untuk menata keteraturan dalam masyarakat itu (Krupiy, 2020). Nilai dan norma sosial tersebut diperoleh melalui proses pengintegrasian berbagai macam kepentingan dan perbedaan antar individu dengan berpedoman pada kultur dan agama yang berlaku dalam masyarakat tersebut. Nilai-nilai dan norma sosial dalam masyarakat yang telah disepakati bersama dijadikan sebagai pedoman hidup, patokan atau ukuran oleh tiap individu maupun kelompok pada setiap interaksi dalam kehidupan bermasyarakat. Jika nilai dan norma tidak berjalan sesuai dengan aturan yang berlaku, maka akan terjadi keguncangan dalam masyarakat (Ridhwan et al., 2015).

Sebagaimana halnya fenomena kemunculan kaum waria dalam masyarakat, keberadaannya merupakan suatu realitas yang tidak bisa ditolak dalam kehidupan bermasyarakat, baik di tinjau dari segi psikologis, sosial, norma, maupun secara fisik. Waria adalah singkatan dari "Wanita pria", waria atau yang sering kita sebut banci, dalam sehari-hari merupakan salah satu penyimpangan sosial dalam kehidupan bermasyarakat. Waria adalah salah satu kaum yang terpinggirkan, bahkan menjadi kaum yang paling terpinggirkan. Banyak orang yang memandang sebelah mata terhadap eksistensi waria, bahkan secara terang-terangan mereka beranggapan negatif, seperti anggapan bahwa waria adalah sampah masyarakat.

Permasalahan sosial yang dihadapi kaum waria termasuk sangat rumit dan kompleks, tidak sedikit kelompok waria menjadi cibiran atau mendapat ejekan dari masyarakat (Idrus \& Hymans, 2014). Untuk itu beragam upaya akan dilakukan oleh kelompok ini agar dapat di terima dalam lingkungan sosialnya. Seperti halnya komunitas waria yang ada di Kecamatan Pangkajene, karena mereka berbeda dengan masyarakat pada umumnya, mereka melakukan penyesuaian diri untuk dapat berinteraksi dengan individu lain sebagaimana layaknya interaksi antar individu maupun kelompok secara umum. Mereka kemudian membentuk suatu komunitas atau kelompok yang mereka namai komunitas waria sebagai wadah untuk dapat dengan mudah berinteraksi dengan sesamanya (Abidin \& Djabbar, 2019; Maghvira et al., 2020; Masnun, 2011; Murtagh, 2013).

Adanya komunitas waria yang dijadikan sebagai wadah untuk berkumpul dan berekspresi, mereka lebih terampil dan memiliki jiwa sosial yang tinggi. Hal ini dapat kita lihat dalam beragam aktivitas yang dilakukan oleh komunitas waria yaitu mereka aktif membantu kegiatan-kegiatan yang dilakukan oleh anggota masyarakat. Selain itu, mereka juga mengadakan kegiatan bakti sosial, pengamanan dalam lingkungan serta kegiatan-kegiatan sosial yang lain. Kegiatan tersebut merupakan cara mereka beradaptasi dalam lingkungan masyarakat sehingga dapat dengan mudah di terima dalam lingkungan sosialnya. 
Memiliki komunitas membuat mereka dapat menyesuaikan diri dengan mudah, sehingga dalam lingkungan sosialnya pun mereka dapat di terima oleh anggota masyarakat yang lain. Perwujudan dari di terimanya komunitas waria dalam kehidupan sosialnya ialah tidak adanya complain dari masyarakat terhadap aktivitas yang dilakukan oleh kelompok waria tersebut, bahkan anggota masyarakat turut menerima dengan baik kegiatan-kegiatan yang dilakukan oleh kelompok waria.

Gambaran bahwa anggota masyarakat menerima keberadaan waria yaitu hubungan sosial antar kelompok waria dengan warga masyarakat tetap terbina dengan baik. Tidak hanya warga masyarakat yang turut menerima komunitas tersebut, akan tetapi pemerintah turut melegitimasi keberadaan komunitas waria. Adanya legitimasi dari pemerintah tersebut sehingga mereka tidak hanya membentuk sebuah komunitas melainkan membuat kelompok dalam skala yang lebih besar yaitu Kerukunan Waria Kabupaten Pangkep (KWKP). Oleh karena itu, untuk mengetahui dan memahami lebih jauh bagaimana adapatasi sosial komunitas waria, sehingga penulis ingin melakukan penelitian dengan judul " Adaptasi Komunitas Waria di Kelurahan Pa'doangdoangan Kecamatan Pangkajene Kabupaten Pangkep”.

\section{METODE}

Di dalam penelitian ini menggunakan metode penelitian kualitatif. Penentuan sasaran informan penelitian dilakukan dengan menggunakan teknik Purpossive Sampling dengan menentukan kriteria (Almenar-Llongo et al., 2021; Creswell \& Creswell, 2017; Rukajat, 2018). Melihat keterbatasan peneliti maka dalam penelitian ini hanya mengambil beberapa informan dengan menarik 14 orang informan dengan kriteria yaitu waria yang tergabung dalam komunitas waria dan warga yang mengetahui serta memahami persoalan terkait. Kemudian melibatkan pihak pemerintah setempat untuk mengetahui sejauh mana penerimaan masyarakat maupun pemerintah tentang keberadaan waria. Teknik pengumpulan data dilakukan melalui observasi, wawancara, dan dokumentasi dengan tahap teknik analisis data kualiatatif yang bersifat deskriptif yaitu mengumpulkan data, reduksi data, menyajikan data, dan menarik kesimpulan (Miles et al., 2014).

\section{HASIL DAN PEMBAHASAN}

\section{Proses Adaptasi Komunitas Waria dalam Masyarakat}

Pada dasarnya perilaku waria muncul karena adanya dorongan dalam diri untuk berperilaku dan menyukai diri atau kepribadiannya sebagai seorang perempuan. Perilaku tersebut muncul tidak dengan sendirinya, akan tetapi terjadi secara alamiah. Keberadaan mereka mempersentasikan perilaku yang jauh berbeda dari laki-laki normal, tetapi bukan pula sebagai perempuan yang normal pula (Maghvira et al., 2020).

Lebih lanjut Maghvira et al., (2020) mengungkapkan bahwa kehadiran seorang waria di dalam sebuah keluarga atau masyarakat seringkali dianggap sebagai aib, sehingga waria senantiasa mengalami tekanan-tekanan sosial. Di dalam pergaulan mereka juga menghadapi konflik-konflik dalam berbagai bentuk, dari cemoohan, pelecehan hingga pengucilan.

Konflik-konflik di atas menyebabkan dunia waria semakin terisolasi dari lingkungan sosial. Olehnya itu, mereka di tuntut harus tetap mampu survive dalam lingkungan yang mengisolasikan dirinya itu. Salah satu cara yang mereka lakukan agar tetap survive mereka 
harus beradaptasi atau menyesuaikan diri dengan lingkungan sehingga dapat di terima dalam lingkungan sosialnya. Hal ini sesuai dengan pendapat (Handman, 2010) yang menyatakan bahwa adaptasi perlu dilakukan oleh setiap individu dalam menghadapi dan menyesuaikan dirinya pada setiap lingkungan yang baru, sehingga menghasilkan keserasian antara individu dengan lingkungan tersebut.

Sementara itu, Mulhearn (1969) menyatakan bahwa penyesuaian diri merupakan proses yang mencakup respon mental dan tingkahlaku individu. Yaitu individu berusaha keras agar mampu mengatasi konflik dan frustasi karena terhambatnya kebutuhan dalam dirinya, sehingga tercapai keselarasan dan keharmonisan antara diri sendiri dengan lingkungannya.

Dengan demikian, komunitas waria perlu melakukan penyesuaian diri agar dapat di terima dalam kehidupan sosialnya. Proses adaptasi tersebut memerlukan waktu yang cukup panjang sehingga dapat betul-betul di terima dalam kehidupan bermasyarakat. Proses adaptasi ini merupakan sebuah strategi untuk mempertahankan eksistensinya. Strategi-strategi itu merupakan satu proses sosial budaya yang pada gilirannya harus dapat mengejawantahkan perilaku waria untuk dapat bertahan dalam ruang sosial tertentu (Rice, 2004).

Dalam teori fungsionalisme struktural, masyarakat dipandang sebagai suatu sistem sosial yang terdiri atas bagian-bagian atau elemen yang saling berkaitan dan saling menyatu dalam keseimbangan (Ritzer \& Ryan, 2010). Hal ini dikenal dengan konsep AGIL yaitu Adapatation, Goal, Integrasi dan Latensi.

Pandangan struktural fungsional dalam konsep adaptasi yaitu setiap individu maupun kelompok harus beradaptasi dengan lingkungan dengan kebutuhan-kebutuhannya. Sebagaimana halnya dengan komunitas waria walaupun secara norma kesusilaan dan norma agama tidak sesuai dengan nilai dan norma yang berlaku dalam masyarakat pada umumnya, akan tetapi selalu ada proses adaptasi sosial yang dilakukan oleh kelompok waria sehingga dapat di terima dalam ruang-ruang sosialnya.

Proses adaptasi tersebut sebagai sarana untuk mencapai tujuan kelompoknya yaitu dapat di terima dalam kehidupan bermasyarakat yang pada akhirnya hubungan sosial antara waria dengan masyarakat pada umumnya dapat terbina dengan baik. Hal ini menjadi bagian dari konsep pencapaian tujuan dari suatu kelompok waria.

Terbinanya hubungan sosial yang baik antar kelompok waria dengan anggota masyarakat merupakan perwujudan dari tercapainya integrasi antara waria dengan kelompok masyarakat. Hal ini sejalan dengan pandangan structural fungsional dalam konsep integrasi yaitu mengatur antarhubungan bagian-bagian dari komponennya. Ia mengelola hubungan di antara kelompokkelompok masyarakat sehingga tercipta hubungan sosial yang seimbang dalam kehidupan bermasyarakat.

Dengan demikian, dapat dipahami bahwa pandangan struktural fungsional adaptasi sosial waria memiliki keterkaitan. Adaptasi yang dilakukan oleh komunitas waria merupakan cara mereka agar di terima dalam lingkungan sosialnya. Boellstorff (2004) mengemukakan bahwa antara perilaku individu dengan lingkungan sosial memiliki hubungan yang saling mempengaruhi. "being waria" bukanlah semata-mata ia harus berperilaku sebagai perempuan, tetapi sejauh mana pula perilaku itu kemudian dapat di terima oleh masyarakat sebagaimana masyarakat dapat menerima perilaku laki-laki atau perempuan.

\section{Penerimaan Masyarakat terhadap Keberadaan Waria}

Di sadari bahwa keberadaan kelompok waria dalam masyarakat belum sepenuhnya mendapatkan peran-peran sosial yang dapat di terima oleh seluruh kalangan masyarakat. Tidak 
jarang mereka masih mendapatkan streotif sebagai kelompok yang berperilaku menyimpang. Pelabelan yang di berikan oleh anggota masyarakat merupakan reaksi terhadap perilaku waria yang berbeda dari perilaku anggota masyarakat pada umumnya.

Teori Labeling (Berliner \& Reuben, 2012) menjelaskan bahwa analisis tentang pemberian cap itu dipusatkan pada reaksi orang lain. Artinya ada orang-orang yang memberikan yang memberi defenisi, julukan, atau pemebri label (definers) pada individu-individu atau tindakan yang menurut penilaian orang tersebut adalah negatif.

Keberadaan komunitas di Keluarahan Pa`doang-doangan walaupun dapat diterima dengan baik oleh masyarakat namun tidak sedikit mereka masih mendapatkan cibiran atau cemooahan dari anggota masyarakat yang lain. Hal ini sesuai dengan pernyataan salah satu anggota komunitas waria bahwa terkadang saya merasa minder ketika berinteraksi dengan di lingkungan karena sering mendapatkan cibiran dari anak-anak.

Pengakuan salah satu anggota komunitas waria menunjukkan bahwa pada dasarnya walaupun mayoritas anggota masyarakat dapat menerima mereka, namun tidak dapat dipungkiri bahwa masih terdapat salah satu anggota masyarakat yang belum semua dapat menerima dengan lapang dada dengan keberadaan waria dalam lingkungan. Hal tersebut terjadi oleh karena dalam konteks budaya, perilaku yang dihadirkan waria tidak hanya dipandang sebagai sebuah tatanan yang menyimpang, namun bahwa bahwa perilaku mereka belum mendapat tempat di dalam peran-peran sosial yang menyatu dengan masyarakat (Ismail et al., 2016; Veitas \& Weinbaum, 2017)

Secara budaya keberadaan waria dianggap sebagai perilaku menyimpang, namun secara sosial, masyarakat kian sadar bahwa keberadaan mereka tidak harus mendapat perlakuan yang tidak sewajarnya. Secara perlahan masyarakat mulai menerima dengan baik kehadiran waria dalam masyarakat. Kini mereka menjalankan peran-peran sosial yang sama dalam masyarakat yang di legitimasi oleh pihak pemerintah setempat.

\section{SIMPULAN}

Proses adaptasi yang dilakukan oleh komunitas waria di Kelurahan Pa`doang-doangan sehingga keberadaan mereka dapat di terima dalam lingkungan sosialnya yaitu mereka menjunjung tinggi nilai-nilai sikap saling mengahargai kepada setiap individu baik dalam kalangan muda atau dewasa dan yang paling penting ialah mereka tetap menjaga etika. Selain itu, mereka memberikan pelayanan terbaik kepada setiap pelanggannya dan aktif dalam kegiatan sosial kemasyarakatan sehingga tercipta rasa emosional yang tinggi dengan warga masyarakat.

Keberadaan waria dalam masyarakat pada awalnya mendapat tekanan-tekanan sosial namun secara perlahan mereka dapat di terima dengan baik dalam masyarakat. Perwujudan dari diterimanya keberadaan komunitas waria di Kelurahan Pa'doang-doangan yaitu mereka tidak hanya di terima dalam lingkungan sosialnya, melainkan mereka mendapat legitimasi dari pemerintah setempat. Kini mereka mendapat peran sosial yang sama dalam lingkungan sosialnya

\section{DAFTAR PUSTAKA}

Abidin, K., \& Djabbar, Y. (2019). A Symbolic Interaction Analysis of Waria (Transgender Women) in Makassar-Eastern Indonesia. Society, 7(2), 195-212.

Almenar-Llongo, V., Muñoz de Prat, J., \& Orero-Blat, M. (2021). Qualitative analysis for joint 
ventures as an entry mode in foreign direct investment. Journal of Business Research, 123, 324-332. https://doi.org/https://doi.org/10.1016/j.jbusres.2020.09.062

Berliner, L. J., \& Reuben, J. (2012). Spin labeling: theory and applications (Vol. 8). Springer Science \& Business Media.

Boellstorff, T. (2004). Playing back the nation: Waria, Indonesian transvestites. Cultural Anthropology, 19(2), 159-195.

Creswell, J. W., \& Creswell, J. D. (2017). Research design: Qualitative, quantitative, and mixed methods approaches. Sage publications.

Handman, C. J. (2010). Schism and Christianity: Bible translation and the social organization of denominationalism in the Waria Valley, Papua New Guinea. The University of Chicago.

Idrus, N. I., \& Hymans, T. D. (2014). Balancing benefits and harm: Chemical use and bodily transformation among Indonesia's transgender waria. International Journal of Drug Policy, 25(4), 789-797. https://doi.org/https://doi.org/10.1016/j.drugpo.2014.06.012

Ismail, A., Sulur, A. H., Akib, H., \& Salam, R. (2016). Snapshot of Society Social-Economic Welfare based on Human Development Index in Polewali Mandar Regency, Indonesia. International Conference on Public Organization VI (ICONPO VI), 847-858.

Krupiy, T. (Tanya). (2020). A vulnerability analysis: Theorising the impact of artificial intelligence decision-making processes on individuals, society and human diversity from a social justice perspective. Computer Law \& Security Review, 38, 105429. https://doi.org/https://doi.org/10.1016/j.clsr.2020.105429

Maghvira, G., Mardiana, L., \& Syukri, S. (2020). Debate on the Plan of Making 'Fiqh Waria': Framing Analysis in Online Media. Jurnal The Messenger, 12(1), 52-62.

Masnun, M. (2011). Waria dan Shalat Reinterpretasi Fikih Untuk Kaum Waria. Musãwa Jurnal Studi Gender dan Islam, 10(1), 123-134.

Miles, M. ., Huberman, A. ., \& Saldana, J. (2014). Qualitative Data Analysis, A Methods Sourcebook (Tjetjep Rohindi Rohidi (ed.); 3 ed.). UI-Press.

Mulhearn, J. (1969). Interfaith marriage and adult religious practice. Sociological Analysis, $30(1), 23-31$.

Murtagh, B. (2013). Genders and sexualities in Indonesian cinema: Constructing gay, lesbi and waria identities on screen. Routledge.

Rice, M. F. (2004). Organizational Culture, Social Equity, and Diversity: Teaching Public Administration Education in the Postmodern Era. Journal of Public Affairs Education, 10(2), 143-154. https://doi.org/10.1080/15236803.2004.12001354

Ridhwan, M. M., Wicaksono, G., Nurliana, L., Bary, P., Suryani, F. T., \& Satyanugroho, R. (2015). Analisis Daya Saing Dan Strategi Industri Nasional Di Era Masyarakat Ekonomi Asean Dan Perdagangan Bebas. Work. Pap. Bank Indones.

Ritzer, G., \& Ryan, J. M. (2010). The concise encyclopedia of sociology. John Wiley \& Sons. 
Faisal Tanjung; Adaptasi Waria: Studi Kasus Komunitas Waria di Kabupaten Pangkep |13

Rukajat, A. (2018). Pendekatan Penelitian Kualitatif (Qualitative Research Approach). Deepublish.

Veitas, V., \& Weinbaum, D. (2017). Living Cognitive Society: A 'digital' World of Views. Technological Forecasting and Social Change, 114, 16-26. https://doi.org/https://doi.org/10.1016/j.techfore.2016.05.002 